\title{
Mella (Olax zeylanica) Leaves as an Eco-friendly Repellent for Storage Insect Pest Management
}

\author{
H. S. D. Fernando* and M. M. S. C. Karunaratne \\ Department of Zoology, University of Sri Jayewardenepura, Sri Lanka
}

Date Received: 10-11-2012 Date Accepted: 12-03-2013

\begin{abstract}
Among the cereals, rice is the most important staple food supplying energy requirements for most of the worlds' population. However during storage a loss of about 10-20\% rice grains occurs due to stored grain pests. Repellents are considered as the best source of protection against insect attack upon stored products as they have potential for the exclusion of stored product pests from grain, and thereby preventing insect feeding and oviposition on food materials. Various plant materials have been utilized effectively through time as safe and ecofriendly insect pest control measures due to their repellent activity. The aim of the present study was to investigate the potential of powdered leaves and leaf extracts of Olax zeylanica as repellents against the rice weevil, Sitophilus oryzae. All the experiments were carried out under laboratory conditions using 1-7 day old unsexed adults. Four different doses $(1.0 \mathrm{~g}, 3.0 \mathrm{~g}, 5.0 \mathrm{~g}$ and $7.0 \mathrm{~g}$ ).of powdered leaves were tested for fumigant repellency in a dual-choice bio-assay apparatus. Repellent action of leaf extracts was evaluated by means of an area preference test using methanol, ethanol and n- hexane as solvents. Repellent effect of powdered leaves against the adult rice weevils was found to be significantly high $(\mathrm{P}<0.05)$ at all doses. The highest repellent effect was produced by $7.0 \mathrm{~g}$ of leaf powder resulting in repellency of $97 \%$, while the lowest dose $(1.0 \mathrm{~g})$ also elicited more than $50 \%$ repellency in weevils indicating a very strong repellent action of the powdered leaves. In comparison, methanol extract of leaves produced the highest repellent effect $(96 \%)$ on weevils whereas n-hexane extract elicited the lowest. Nevertheless, at higher concentrations all three extracts produced more or less significantly similar repellent effect on the weevils. The findings of the present study suggest that certain active materials of Olax zeylanica leaves have potential to act as a grain protectant and may be exploited for the control of Sitophilus oryzae in rice storage in an environment-friendly way.
\end{abstract}

Keywords: Olax zeylanica, Sitophilus oryzae, Repellent effect, Stored rice

\section{Introduction}

The practice of using plant derivatives or botanical insecticides in agriculture dates back at least two millennia in ancient China, Egypt, Greece and India (Isman, 2006). In many developing countries, utilization of locally available plant materials to protect stored products against pest damage is common practice in traditional farm storage systems (Akob \& Ewete, 2007). As Martin \& Gopalakrishnan (2005) state these plant materials were not only used as insecticides but also as insect repellents and insect antifeedants.

*Correspondence: sacdinu@gmail.com

Tel: +94112804515

ISSN 2235-9370 Print / ISSN 2235-9362 Online (C2013 University of Sri Jayewardenepura

64 
Plants have developed effective morphological and chemical defense mechanisms that ensure survival under rough environmental conditions and in the presence of natural enemies. These chemical defenses either may produce mortality of the insect by acting as an insecticide or may affect common biochemical and physiological functions and act as repellents, antifeedants or oviposition inhibitors. Excessive use of conventional pesticides disrupts natural pest control mechanisms and enhances development of pesticide resistant insect strains. In addition, they may have lethal effects on non-target organisms and may pose toxicity to consumers (Dubey et al., 2008; White \& Leesch, 1995).

Compared to conventional pesticides, crude or formulated botanical pesticides tend to have broadspectrum activity, and are relatively specific in their mode of action, easy to process by the small scale farmers and would be safe for the higher organisms (Viglianco et al., 2008). According to Prakash et al. (2008) these pesticides do not contribute to resistance development or pest resurgence, nor do they cause negative effects on non-target organisms and also they do not affect food quality.

Deterioration of the quality and quantity of the food materials is a major problem in storage systems. Stored rice seeds and milled rice is prone to be infested by rice weevils, Sitophilus oryzae L. (Coleoptera: Curculionidae), causing heavy economic losses. Adult weevils feed on rice grains and lay eggs within the grain surface and the larvae develop inside the grain thus feeding preferentially on the germ of the grain. Because both larvae and adults feed on germ of the grain, the grain is completely damaged beyond any use. Prevention of food losses during postharvest storage without creating environmental problems is therefore, of paramount economic importance. Hence, the primary objective of this investigation was to evaluate the repellent activity of leaves of Olax zeylanica against adult Sitophilus oryzae as identification of effective as well as locally available botanicals will provide a sustainable alternative in controlling storage insect pests.

\section{Materials and methods}

\subsection{Host material}

Whole and un-infested white raw rice was used for bioassays and as rearing media to prevent contamination of laboratory cultures. Unsexed, 1-7 days old adult rice weevils were used for bioassays. All bioassays were carried out under ambient laboratory conditions of $29 \pm 2{ }^{\circ} \mathrm{C}$ and $84 \pm 2 \% \mathrm{RH}$.

\subsection{Preparation of plant powder}

Freshly collected leaves of Olax zeylanica were washed thoroughly under running tap water to remove any contaminants. These were then shade dried until the water was evaporated. The dried leaves were ground to fine powder using a domestic electric grinder (Multinational®, 2102, India).

\subsection{Preparation of plant extracts}

Hundred grams of freshly ground leaf powder was mixed with $350 \mathrm{ml}$ of solvent and kept for 48 hours while stirring from time to time. Three solvents, methanol $(99.85 \%)$, ethanol (96\%) and n- hexane $(95 \%)$ were used for the bioassays. After 48 hours each of the resulting crude extract was filtered using Filtermann ${ }^{\circledR}(125 \mathrm{~mm})$ filter papers. The filtered extract was then concentrated using a vacuum rotary evaporator (Microsil, India) at $65^{\circ} \mathrm{C}$ until the extract was reduced approximately to $60 \mathrm{ml}$ and was considered as the stock solution. A series $(1 \mathrm{ml}, 3 \mathrm{ml}, 5 \mathrm{ml}, 7 \mathrm{ml}$, and $10 \mathrm{ml})$ of this stock solution was dissolved in 10ml of the appropriate solvent and five dilutions (T1, T2, T3 T4 and T5) each were made.

\subsection{Fumigation repellency assay for plant powders}

The bioassay apparatus for fumigation repellency test consisted of two plastic containers separated by a perforated lid (Figure1). Powdered leaves were introduced into the bottom container (height10cm, 
diameter $6 \mathrm{~cm}$ ) and the upper container consisted of $50 \mathrm{~g}$ of rice. The upper part of this container was perforated with a thick needle to allow the insects escape from the container if they were repelled by the fumes emanating from the powdered leaves.

The bioassay apparatus was placed inside a larger container (height $25 \mathrm{~cm}$, diameter $10 \mathrm{~cm}$ ) to trap the weevils that escaped through the holes in the test container. The mouth of the larger container was covered with a piece of polythene which has tiny holes in it to allow ventilation.

Test insects were then introduced into the container consisting rice, and the holes on the container was covered with a sticky tape for 10 minutes to let the introduced insects settle down inside. A similar bio-apparatus without leaf powder was used as the control. Number of escaped insects was recorded after half an hour and one hour of introduction of weevils. Four doses $(1.0 \mathrm{~g}, 3.0 \mathrm{~g}, 5.0 \mathrm{~g}$ and $7.0 \mathrm{~g})$ of powdered leaves and the control were assayed against the weevils. This test was replicated five times.

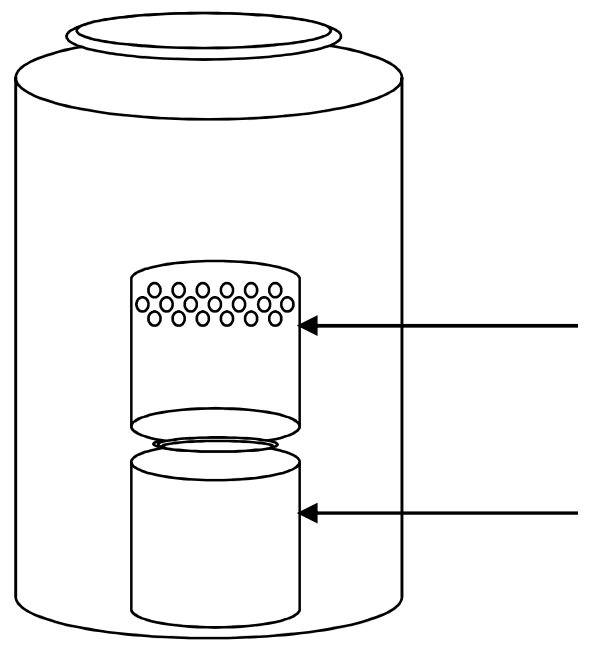

Perforated container with $50 \mathrm{~g}$ rice and 30 insects

Container with plant powders

Figure1: Bioassay apparatus for the fumigation repellency test

\subsection{Repellency assay for leaf extracts}

Repellency of adult weevils for leaf extracts was tested using an area preference test. The test area consisted of a Filtermann ${ }^{\circledR}(125 \mathrm{~mm})$ paper disc that was cut into two parts. One part of the filter paper was treated with $1 \mathrm{ml}$ of the prepared extract as uniformly as possible and the other part was treated with $1 \mathrm{ml}$ of the solvent which was considered as the control. Both the treated half and the control half of the filter paper were then air dried to evaporate the solvent completely. A full disc was carefully re-made by attaching the treated part to the control part with adhesive tape and then placing it in a petri-dish. Before the onset of the experiment, glycerin was applied on to the side walls of the petri-dish to prevent the weevils moving to the top. $10 \mathrm{~g}$ of rice seeds were distributed uniformly on the remade full disc as an attractant for the weevils to stay on the paper. Ten unsexed adult weevils were then released on to the centre of each filter paper disc and a lid was placed over the Petri dish. Thirty minutes after the introduction, the adult weevils present on each half of the filter paper was counted. Ten replicates were made for five concentrations of three solvent-plant extracts of $O$. zeylanica.

\subsection{Analysis of Data}

Statistical package "Minitab 14" was used for all the statistical analyses. Data obtained were subjected to one way analysis of variance (ANOVA). Tukey's multiple comparison test $(p<0.05)$ was used to separate mean values of the experiments. 


\section{Results and Discussion}

According to Figure 2, it is clear that the volatiles of leaf powders of $O$. zeylanica played a significant role on rice weevils by repelling them away from the treated chamber to the outer container. One hour after introduction of weevils, the highest repellency $(88.67 \%)$ was observed for $7 \mathrm{~g}$ of leaf powder.

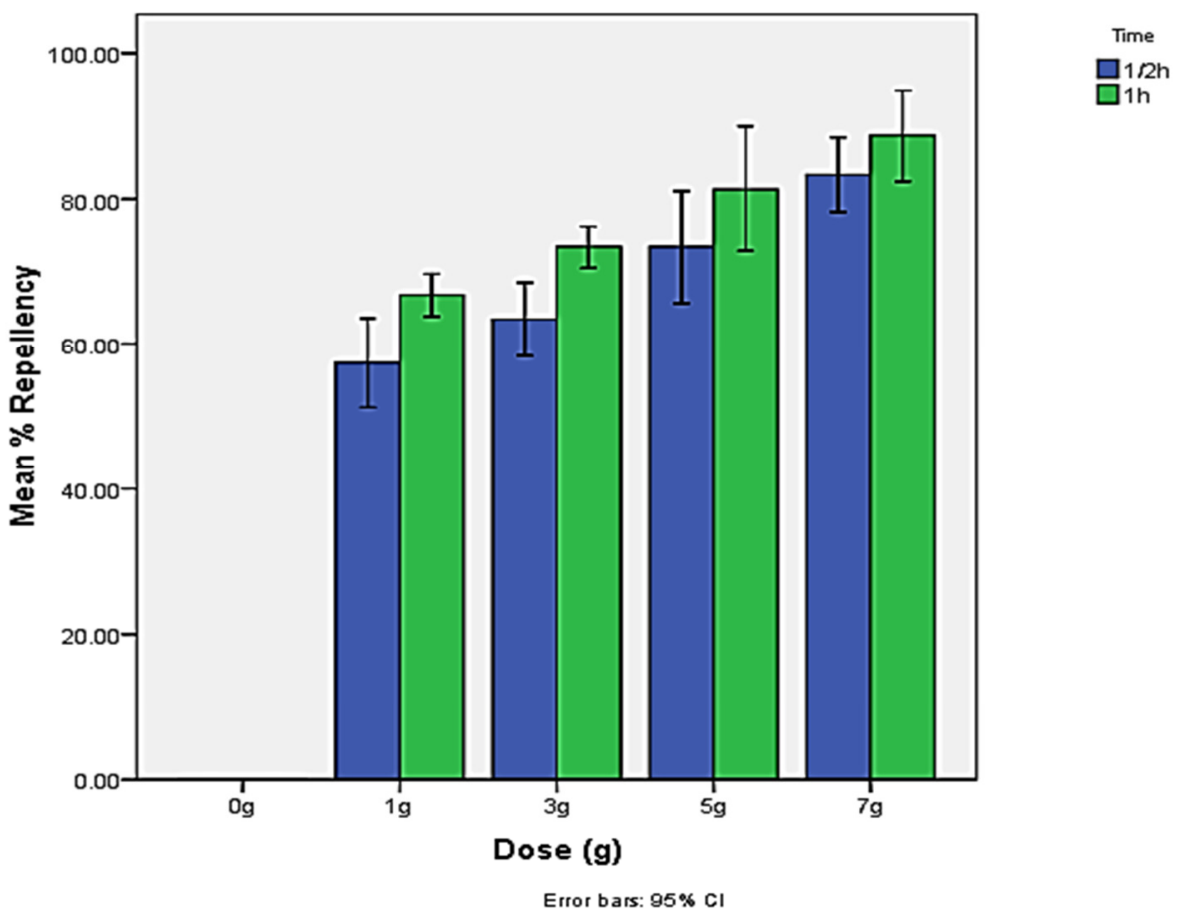

Figure 2: Mean percentage repellency of $S$. oryzae to different doses of plant powders $*$ Mean Repellency \pm SD for ten replicates $(n=100)$

The repellency rate of methanol, ethanol and n- hexane extracts at different doses on $S$. oryzae is presented in Table 1. The findings of this experiment revealed that the rate of repellency increased with the increase of dose level. For this bioassay, solvents with different polarity were selected in order to extract differently polarized compounds from $O$. zeylanica leaves into the solvents

Table1: Repellency of $S$. oryzae to different concentrations of three plant solvent extracts in an area preference test.

\begin{tabular}{crrr}
\hline & \multicolumn{3}{c}{ \% Repellency \pm SD } \\
\cline { 2 - 4 } Treatment & Ethanol & n- Hexane \\
\hline T1 & $75.0 \pm 0.85^{\mathrm{ab}}$ & $68.0 \pm 0.79^{\mathrm{b}}$ & $57.0 \pm 1.16^{\mathrm{b}}$ \\
T2 & $78.0 \pm 1.03^{\mathrm{ab}}$ & $85.0 \pm 1.43^{\mathrm{a}}$ & $67.0 \pm 0.95^{\mathrm{b}}$ \\
T3 & $93.0 \pm 0.95^{\mathrm{a}}$ & $86.0 \pm 0.84^{\mathrm{a}}$ & $68.0 \pm 0.79^{\mathrm{b}}$ \\
T4 & $94.0 \pm 0.84^{\mathrm{a}}$ & $86.0 \pm 0.96^{\mathrm{a}}$ & $80.0 \pm 1.33^{\mathrm{ab}}$ \\
T5 & $96.0 \pm 0.52^{\mathrm{a}}$ & $94.0 \pm 0.69^{\mathrm{a}}$ & $83.0 \pm 1.06^{\mathrm{a}}$ \\
Probability & $p<0.05$ & $p<0.05$ & $p<0.05$ \\
\hline
\end{tabular}


Among all the concentrations and solvents tested, methanol extract was found to be the one with the strongest repellent effect on $S$. oryzae with percentage repellency of $96 \%$ at the highest concentration followed by ethanol extract (94\%). Hexane extracts elicited significantly lower repellency rate when compared with Ethanol and Methanol extracts Nevertheless at higher concentrations repellent effect of all three extracts were not significantly different $(\mathrm{P}<0.05)$ from each other in spite of their different polarity levels. This suggests that the repellent activity of the leaf extracts may be due to a combination of different types of allelochemicals. Regardless of the solvent used, all three extracts at all concentrations produced considerably high repellent activity in weevils signifying that even lower amounts of the leaf material could be used effectively as a repellent against the rice weevil.

The present study reveals that the repellent effect of $O$. zeylanica on $S$. oryzae was directly attributable to the volatiles emitted from the leaves as the weevils were not in direct contact with the leaf powder or extracts. Moreover, previous studies conducted on fumigant toxic effect of O. zeylanica leaf volatiles on $S$. oryzae have shown $100 \%$ mortality in weevils even at small doses (Fernando \& Karunaratne, 2012). These observations verify the fact that some volatile constituents of O. zeylanica leaves elicit both repellent and insecticidal effects. In view of these results it is quite apparent that $O$. zeylanica leaves can be used as an effective fumigation agent in controlling rice weevil infestations.

In recent years, many research workers have given greater attention to the control of stored grain pests especially $S$. oryzae using leaf and seed powders, extracts and essential oils of various plant species. Mishra et al (2012) demonstrated that essential oils of Eucalyptus globulus and Ocimum basilicum leaves were effective in repelling rice weevils. Khani et al (2011) evaluated the toxicity and repellency of crude extracts of Piper nigrum and Jatropha curcas on S. oryzae adults and stated that both species of plant extracts could be applied against rice weevil effectively. Leaf powder of Mentha viridis has been observed to be highly effective as a repellent to $S$. oryzae (Gunaratne \& Karunaratne (2009).

The findings of the present study indicate that active compounds present in the powders and extracts of $O$. zeylanica leaves may play a role in the biological activity against adult $S$. oryzae. These compounds may independently or jointly contribute to cause repellent action against $S$. oryzae. These results also suggest that leaves of this plant have potential to provide rice grain protection and may be exploited for rice weevil control in storage in an environmental friendly way. However, further studies are needed to isolate and identify the active chemical compounds responsible for this activity and to examine the effect of powdered leaves and leaf extracts of $O$. zeylanica against a wider-range of storage insect pests.

\section{References}

Akob, C. A., \& Ewete, F. K. (2007). The efficacy of ashes of four locally used plant materials against Sitophilus zeamais (Coleoptera: Curculionidae) in Cameroon. International Journal of Insect Science, 27(1), 21-26.

Dubey, N. K., Srivastava, B. and Kumar, A. (2008). Current Status of Plant Products as Botanical Pesticides in storage pest management. Journal of Biopesticides, 1(2):182 - 186.

Fernando and Karunaratne, M. M. S. C. (2012). Ethnobotanicals for Storage Insect Pest Management: Effect of powdered leaves of Olax zeylanica in suppressing infestations of rice weevil Sitophilus oryzae (L.) (Coleoptera:Curculionidae), Journal of Tropical Forestry and Environment Vol. 2, No. 01, $20-25$

Gunaratne, T. V. N. M. and Karunaratne, M. M. S. C. (2009). Laboratory evaluation of some Sri Lankan plants as post-harvest grain protectants for the control of rice weevil Sitophilus oryzae. Vidyodaya Journal of Science, 14 (2) : 
Isman, M.B. (2006). Botanical insecticides, deterrents, and repellents in modern agriculture and an increasingly regulated world. Annual review of Entomology, 51, 45-66.

Khani, M., Awang, R. M., Omar, D., Rahmani, M., \& Rezazadeh, S. (2011). Tropical medicinal plant extracts against rice weevil, Sitophilus oryzae L. Journal of medicinal plants research, 5(2), 259-265.

Martin, R. J. and Gopalakrishnan, S. (2005). Insecticidal activity of aerial parts of Synedrella nodiflora GAERTN (Compositae) on Spodoptera litura (Fab.). Journal of Central European Agriculture, 6(3), 223-228.

Mishra, B. B.,Tripathi, S. P. and Tripathi, C. P. M. (2012). Repellent effect of leaves essential oils from Eucalyptus globulus (Mirtaceae) and Ocimum basilicum (Lamiaceae) against two major stored grain insect pests of Coleopterans. Nature and Science, 10(2):50-54.

Prakash, A. Rao, J. and Nandagopal, V. (2008). Future of botanical pesticides in rice, wheat, pulses and vegetables pest management. Journal of Biopesticides, 1(2):154 - 169

Viglianco, A. I., Novo, R. J., Cragnolini, C. I., Nassetta, M., \& Cavallo, A. (2008). Antifeedant and repellent effects of extracts of three plants from Córdoba (Argentina) against Sitophilus oryzae (L.) (Coleoptera: Curculionidae). BioAssay, 3(4), 1-6.

White, N.D.G.and LEESCH, J.G. (1995). Chemical control. In: Integrated management of insects in stored products (eds. B. Subramanyam and D.W. Hagstrum). Marcel Dekker, New York, pp. 287-330. 